\title{
Reproduction of human potential in the Ural federal district in Russia under the new normal conditions
}

\author{
Victor Barkhatov ${ }^{1, *}$ \\ ${ }^{1}$ Chelyabinsk State University, 454001, Br. Kashirinykh str., 129, Chelyabinsk, Russia
}

\begin{abstract}
The article analyzes the dynamics of the main indicators characterizing the conditions and results of human potential development in the regions included in the Ural Federal District of Russia, including labor productivity. Particular attention is paid to assessing the regions' intellectual potential, indicators of development of a scientific activity, and reproduction of scientific potential. The trends of the number of scientific organizations, the number of scientific workers and graduate students, and research costs are analyzed. The development of innovation infrastructure facilities in the regions of the Ural Federal District is considered separately. The conclusion is drawn about a significant and increasing unevenness in the conditions of a new normal.
\end{abstract}

\section{Introduction}

The industrial mode of production has exhausted its potential, and its preservation makes the regions depressed, losing their development opportunities in the coming years. Over the past decade, regional economies have faced several problems, which together determine the conditions of a "new normal" for the region's modern development. Studying the features of the development of Russia's regions in these conditions is an essential and urgent task for today. Problems and prospects of changing economic conditions and embedding the Russian economy in the conditions of the "new normal" considered by S. Glazyev [1], V. Bochko [2], O. Evstigneeva [3], Ya. Silin with colleagues [4], A. Tatarkin [9]. My colleagues and I also pointed at the importance of analyzing regional development unevenness in the newly emerging conditions $[6,7]$. The problems of uneven development of the Russian economy have been considered earlier, and outstanding results were obtained by A. Vorotnikov [8], V. Ryazanov [9], V. Seliverstov [10], A.Shastitko [11].

New normal (concerning the regional economy) is a system of ideas developed among regional actors about the level of socio-economic development based on the existing production, technological, financial, and human potential for a particular region. Moreover, for different regions, the content of "normality" will depend on their socio-economic development level. Depending on this level, regions can be divided into regions of the Center (their economic potential allows for high rates of socio-economic development and

\footnotetext{
${ }^{*}$ Corresponding author: ieo-science@csu.ru
} 
creates opportunities for a transition to a new way of life) and peripheries (which do not have such potential) [1].

The dependence of the peripheral regions on the Center reduces their need to form their own "intellectual melting pots," in which intellectual elites are created that can overcome the technological backwardness of the regions. In Russia, where the dependence of the national economy on the Center is high, the development of regions is largely determined by the Center's situation. The Center, having limited resources, is forced to make decisions about their concentration only in a limited number of areas. The development of the national and regional economies in a given period urgently requires the transition of the regional economies to a new reality, to a new normal. The term was introduced by the scientific revolution Mohamed A. El-Erian [12]. R. McNaimy [13] and D. Pletnev [14] wrote about the new normal. Under the new normal, they understand the time of new opportunities for investors who can take on investment risks.

\section{Methodology and data}

Based on the above approaches, it is necessary to study the opportunities, resources, and abilities of the Ural Federal District's regions, the transition to a new normal, technological structure, and the prerequisites for economic growth. The research uses data related to the development of new technological structures, the conditions for the development of human potential, and its result, expressed in terms of "labor productivity." The analysis is based on data from Rosstat on the development of Russian regions in 1996-2017 and data from regional development institutions.

\section{Results}

The level of technological and economic development reflects the basic indicator of labor productivity growth. A sharp decrease in the increase (up to a decrease) in labor productivity was observed in 2009 . The decrease in labor productivity in the regions was: in the Sverdlovsk region - $18.9 \%$, in the Chelyabinsk region - $23.3 \%$, in the Kurgan region $3.3 \%$, in the Tyumen region $-14.3 \%$. From 2012 to 2017 , a decrease in labor productivity was observed in all regions, or close to 0 (Fig. 1).

The new economic structure presumes a different than today, the structure of the regional economy, based on the use of all available resources and industries based on old technologies. Contradictions between the old industrial economic structure and the nascent new structure of production are developing and deepening. Acceleration of processes, and the transition to a new quality largely depend on regional elites' mobility and economic interests, their ability to give impulses to new development. The transition to a new technological structure depends on the institutional environment of the regions. The speed of new factors occurrence creates the conditions for the region's transition to a new normal, the Centers' transformation capable of creating the conditions for such a transition and their ability to pull the periphery to the Center.

Despite the growth of the regions main indicators, the development of the Center and the periphery is impossible without the "intellectual melting pots" formation. It can significantly affect the qualitative transformation of the regional economies. Let us analyze the indicators characterizing the "intellectual melting pots" of the Ural Federal District regions, through the indicators of the scientific potential of the regions of the Ural Federal District. The highest scientific potential is characteristic of the Sverdlovsk region. From 2010 to 2017, the number of organizations carrying out research and development has grown in this region. In 2010 there were 100 such organizations and in 2017 - 109 
organizations (Fig. 4). The number of employees increased from 20,378 to 21,212 people. The number of researchers with advanced degrees increased from 2,228 in 2010 to 2,674 in 2017. The number of researchers with academic degrees (Doctors of Sciences) was 582 in 2010 and 644 in 2017, respectively, with academic degrees of Candidate of Sciences 1047 and 2030 (see Table 1). Dramatically different in these indicators Chelyabinsk, Tyumen region. Low scientific potential in the Kurgan region as a peripheral region. In 2017, the number of organizations performing research and development in the Chelyabinsk region amounted to 62 organizations, in the Tyumen region - 62, in the Kurgan region - only 14 organizations, which are represented, among other things, by branches with head offices in Yekaterinburg. The number of personnel engaged in scientific research was 15167 in the Chelyabinsk region, 8260 in the Tyumen region, and 629 in the Kurgan region. The number of researchers with academic degrees in the regions: in Chelyabinsk, there are only 1138, of which: doctors of science - 292, candidates of science - 846, in Tyumen - only 908, of which doctors of science - 183, candidates of science - 705, in Kurgan - only 629 Of these, there were 39 doctors of sciences, 116 candidates of sciences. The total number of researchers with advanced degrees was also different: in the Sverdlovsk and Tyumen regions, there was a decline, while there was an almost $20 \%$ increase in the Chelyabinsk region. In this respect, the Kurgan region held stable "depressive" positions (Fig. 2-3)

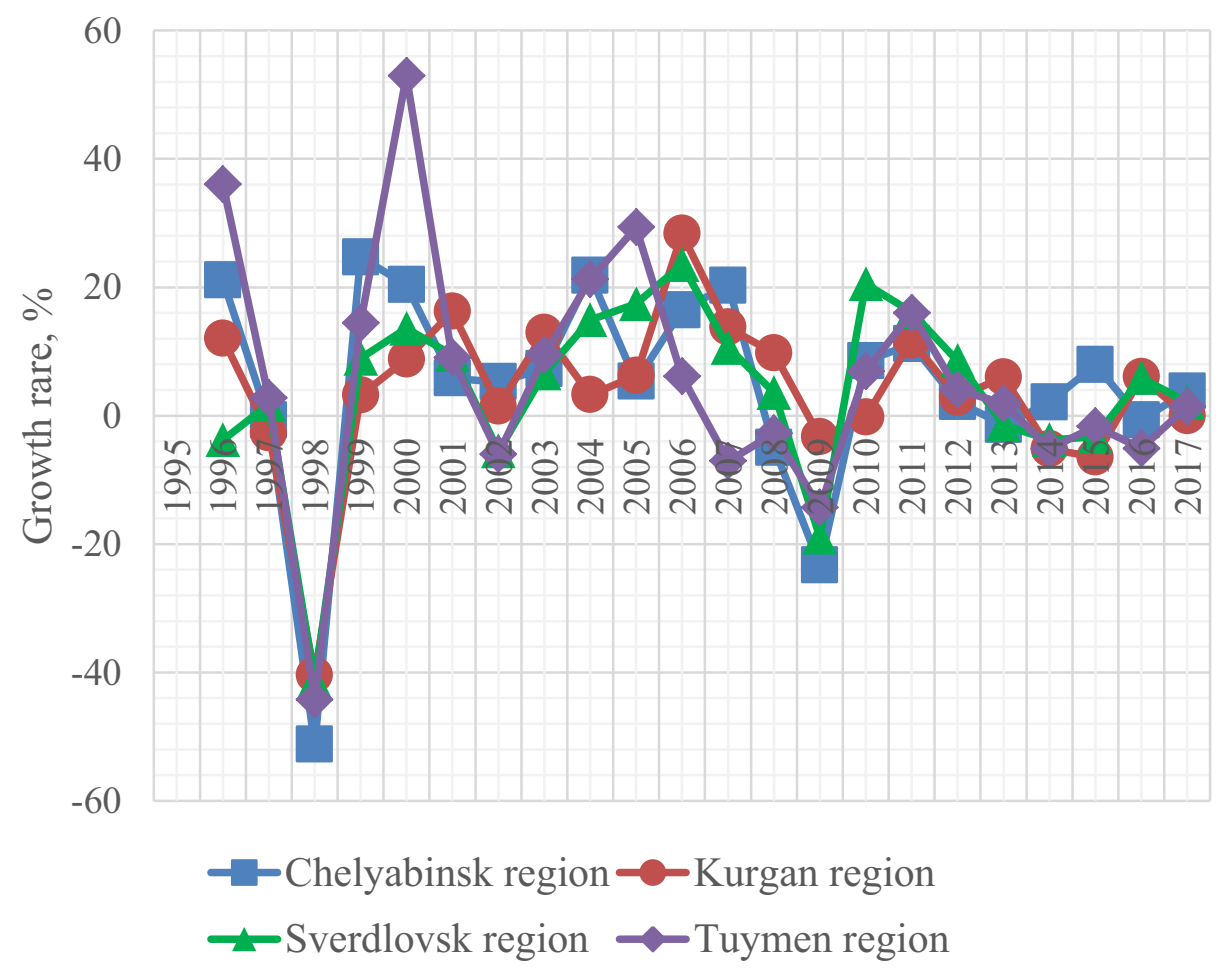

Fig. 1. Labor productivity growth by regions of the Ural Federal District (1996-2017).

Also noteworthy are the difficulties with the training of highly qualified personnel graduate students. The data on defenses is even more deplorable, but even the trends in the number of students show that the decline is $1.5-2$ times. Naturally, this affects the quality of scientific research and the reproduction of the potential of higher education, and in general, the training system. 


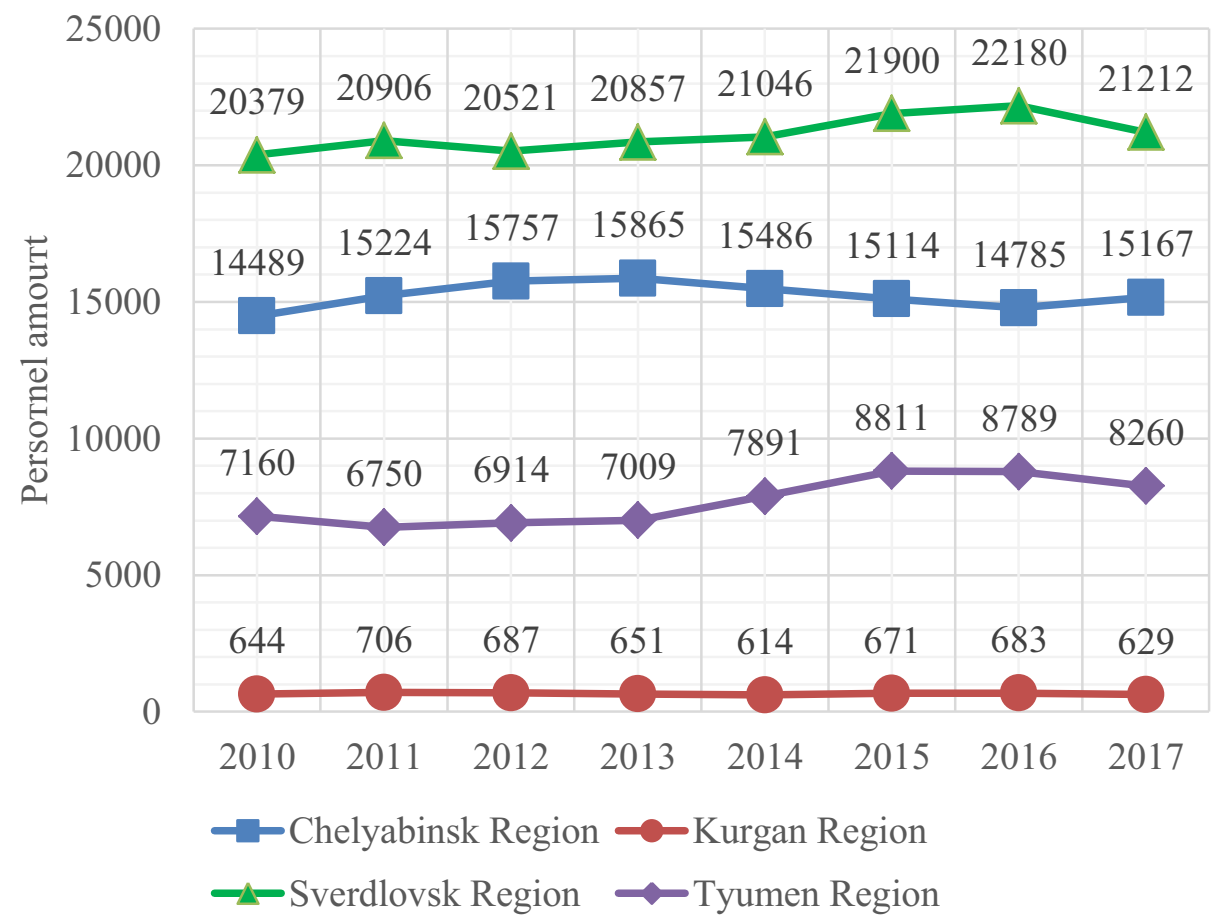

Fig. 2. The number of personnel engaged in research in the Ural Federal District (2010-17).

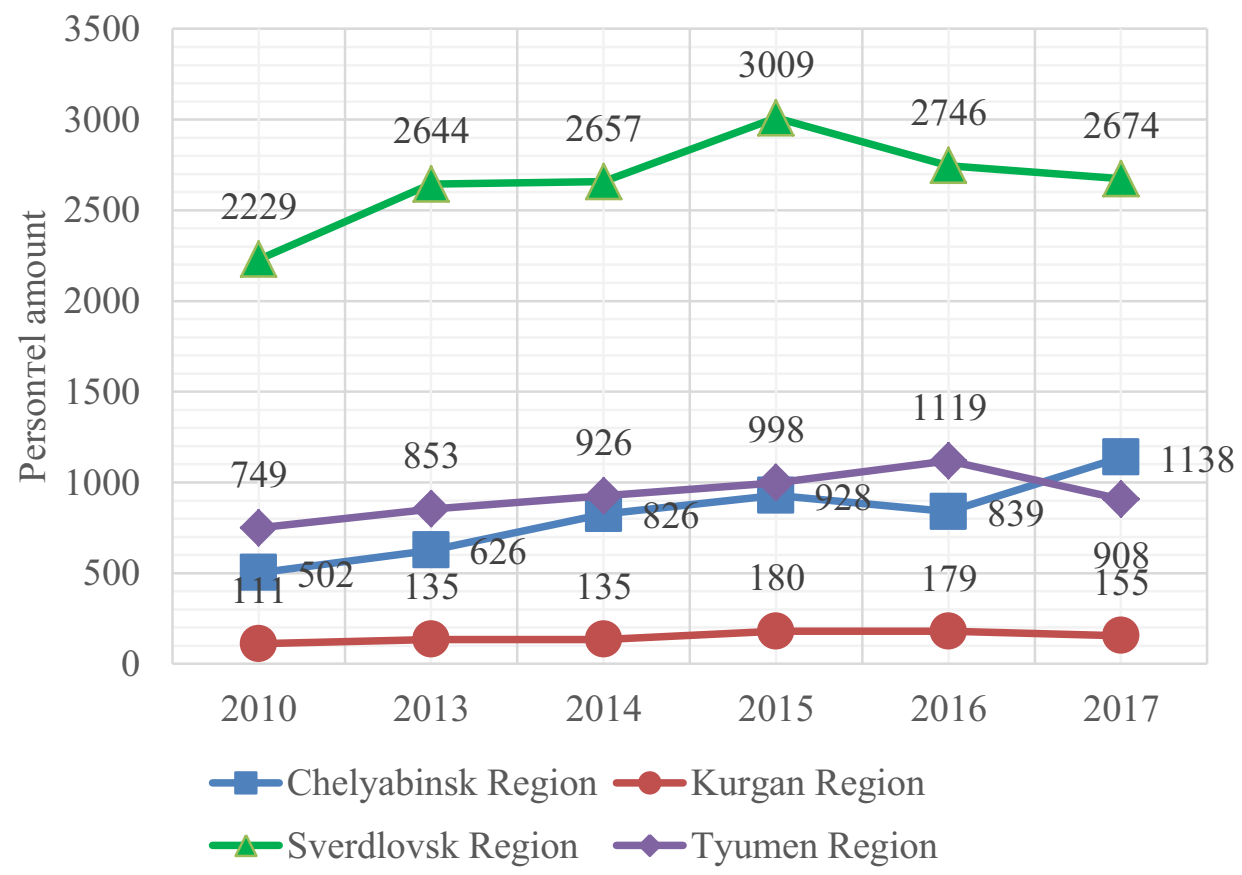

Fig. 3. Number of researchers with advanced degrees in the regions of the Ural Federal District (2010-17). 
On the Ural Federal District territory, an economic and organizational structure has emerged, represented by the complex interdependence and interconnections of territories with different levels of socio-economic development. The basis of the industrial potential of the regions is the industrial structure. In the regions, prerequisites for the transition to a new technological structure are being formed, but they are point-like. In the regions, conditions have not been created for realizing the potential of the region's industry and "intellectual melting pots." The ability to make the transition to new normal is, first of all, great for the Center (constituent entity of the district) of the Sverdlovsk region. Under certain conditions, such opportunities arise in the Chelyabinsk region. It is difficult to carry out this transition to the peripheral region (Kurgan region). Creating the conditions for such a transition is associated with additional resources, not the area itself.

Domestic research costs increased from 2010 to 2017 for all regions and types of work. Internal spending on research and development in the Sverdlovsk region increased from 12,712 to $32,186.3$, in the Chelyabinsk region from $8,906.8$ to $22,381.1$, in the Tyumen region from 7,609.5 to $16,373.6$, in the Kurgan region from 213.5 to 346.7 million rubles. The highest internal costs for research and development are characteristic of the Center of the Ural Federal District; they are 93 times more than the periphery's costs.

The internal costs of research and development by type have the following trends. In 2017, the Center (Sverdlovsk Region) spent 3722.7 on basic research among basic costs, 1746.6 on applied research, and 23948.3 on development. While the Chelyabinsk region, respectively - 435, 1162, 15665, Tyumen -755.3, 496.1, 10117.7, Kurgan - 24.3, 135.9, 186.1. As the data show, the scientific potential is most developed in the Center (Sverdlovsk region) and poorly developed in the Kurgan region. A positive trend boils down that developments in all regions occupy a high share in internal costs of research and development by type of work. In the Tyumen region, costs are higher for applied internal types of work (Table 1).

Table 1. Structure by types of internal costs for research and development in the Ural Federal District (2010-17).

\begin{tabular}{|c|c|c|c|c|c|c|}
\hline \multirow[b]{2}{*}{ Regions } & 2010 & 2013 & 2014 & 2015 & 2016 & 2017 \\
\hline & \multicolumn{6}{|c|}{ Total in R\&D } \\
\hline Chelyabinsk Region & 7837.1 & 11780.6 & 10132.7 & 11996.4 & 15756.6 & 17262.1 \\
\hline Kurgan Region & 210.6 & 265.8 & 266.4 & 280.2 & 330.2 & 346.4 \\
\hline Sverdlovsk Region & 12082.5 & 20379.6 & 24375.5 & 24692.8 & 26883.9 & 29414.7 \\
\hline \multirow[t]{2}{*}{ Tyumen Region } & 6979.7 & 8936.4 & 10248 & 13581.5 & 13416.8 & 15834.1 \\
\hline & \multicolumn{6}{|c|}{ Fundamental Research } \\
\hline Chelyabinsk Region & 317 & 423.2 & 473.8 & 522 & 392.5 & 435 \\
\hline Kurgan Region & 16.6 & 42.2 & 72.7 & 28.7 & 21.2 & 24.3 \\
\hline Sverdlovsk Region & 2197.2 & 2997.9 & 3573.3 & 3926.8 & 3568.1 & 3722.7 \\
\hline \multirow[t]{2}{*}{ Tyumen Region } & 463.7 & 836 & 963.3 & 869.6 & 879.3 & 755.3 \\
\hline & \multicolumn{6}{|c|}{ Applied Research } \\
\hline Chelyabinsk Region & 319.8 & 545.8 & 643.2 & 871.4 & 926.5 & 1162.1 \\
\hline Kurgan Region & 100.1 & 81.2 & 56.9 & 114 & 149 & 135.9 \\
\hline Sverdlovsk Region & 777.6 & 1570.1 & 1417.7 & 1498 & 1613 & 1743.6 \\
\hline \multirow[t]{2}{*}{ Tyumen Region } & 917.9 & 1099.6 & 1420.6 & 4360.4 & 3887.8 & 4961.1 \\
\hline & \multicolumn{6}{|c|}{ Development } \\
\hline Chelyabinsk Region & 7200.3 & 10811.6 & 9015.8 & 10603 & 14437.5 & 15665 \\
\hline Kurgan Region & 93.9 & 142.4 & 136.8 & 137.5 & 160 & 186.1 \\
\hline Sverdlovsk Region & 9107.6 & 15811.6 & 19384.5 & 19268.1 & 21702.7 & 23948.3 \\
\hline Tyumen Region & 5598.1 & 7000.8 & 7864.1 & 8351.5 & 8649.7 & 10117.7 \\
\hline
\end{tabular}


The primary forms of innovative infrastructure are disclosed in fig. 4. The dynamics of the number of innovative infrastructure in the Ural Federal District and regions are presented on federal information resources. The figures show the subjects of priority development in the Sverdlovsk, Chelyabinsk, Kurgan, and Tyumen regions in 2017 and in 2019. In the Sverdlovsk region, there are three such territories, in Chelyabinsk - 5, in Kurgan - three. Recently, industrial and technological clusters have been commissioned in the regions to develop. In the Sverdlovsk region in 2019, there were eight such, in Chelyabinsk - five, in Kurgan - two. Industrial parks are being developed. In 2019, there were six industrial parks in the Sverdlovsk region, three in the Chelyabinsk region, two in the Kurgan region, and two in the Tyumen region. Recently, technology parks were created. In 2019, there were three of them: in the Sverdlovsk region - three, in the Chelyabinsk region - one, in the Tyumen region - one. In 2019, in the Sverdlovsk region works eight business incubators, respectively in the Chelyabinsk region - three, in the Kurgan region one, in the Tyumen region - two.

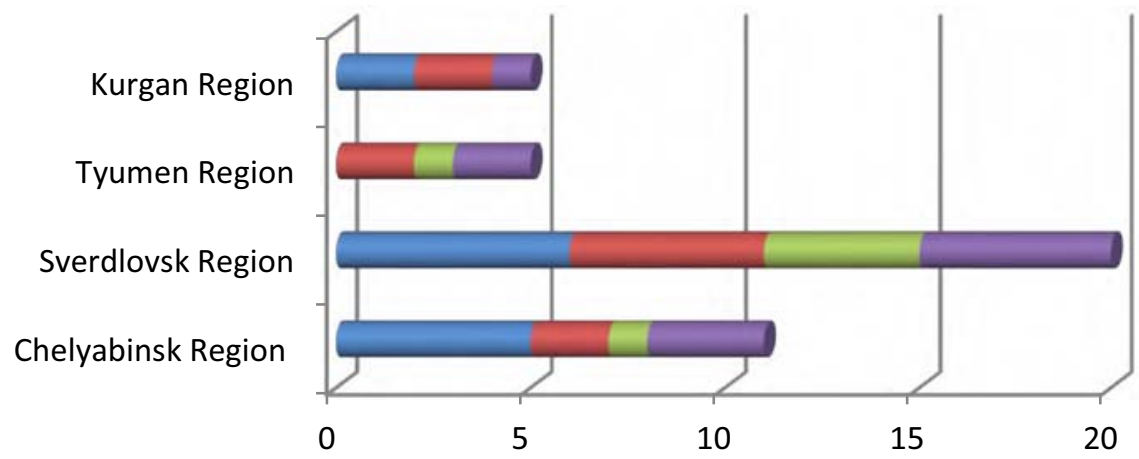

- Industrial technological clusters $\square$ Industrial parks

- Technoparks Business-incubators

a

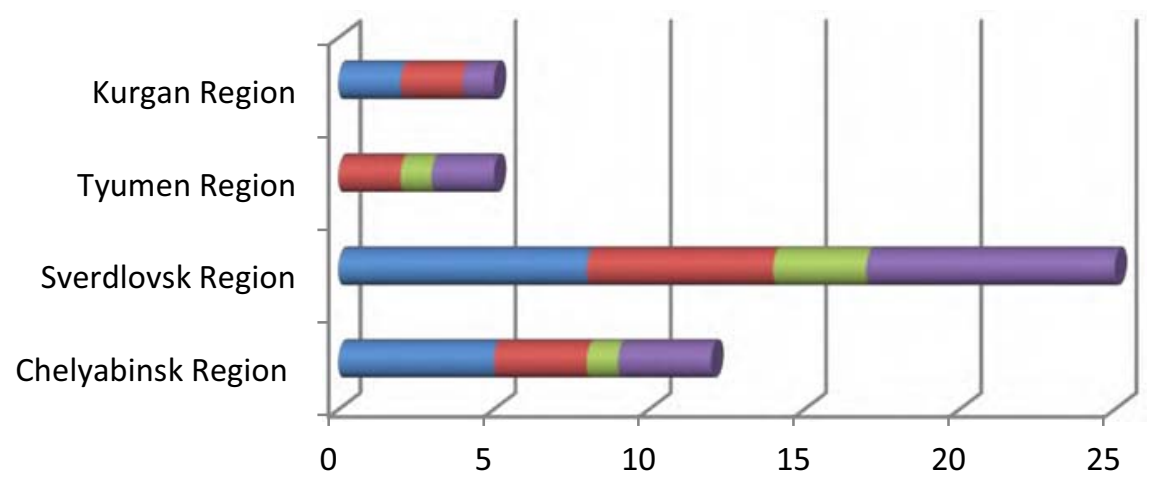

b

Fig. 4 Changes in the number of innovation infrastructure facilities in the Ural Federal District regions, (a - 2017, b -2019).

In general, the purpose of the Center is to help align the socio-economic development of the regions. It is necessary to carry out the transition from the formation of a strategy for 
the socio-economic development of the region to the federal district's strategy, taking into account the existing production, economic, scientific potentials of all regions.

\section{Conclusion}

Thus, the spatial development of the Ural Federal District regions under the new normal is characterized by high unevenness, which intensifies as the specifics of the "new normal" are revealed. The contrast between the Center and the periphery regions in the reproduction of scientific potential and its application in the real sector of the economy looks particularly sharp. Moreover, the development of innovative infrastructure as a prerequisite for the emergence of "intellectual melting pots" is prolonged, especially in peripheral regions.

\section{References}

1. Glazyev S.Y., Ajvazov A.E., Belikov V.A. (2018) Economy of Region, vol. 14, no. 1, p. 1-12.

2. Bochko V.S. (2016) Ekonomy of region, vol. 12, no. 2, p. 342-358.

3. Yevstigneyeva L., Yevstigneyev R. (2014) Voprosy ekonomiki, no. 11, p. 140-155. [in Rus.].

4. Silin YA. P. (2016) Ekonomy of region, vol. 12, no. 3, p. 714-725. [in Rus.].

5. Tatarkin A., Romanova O., Akberdina V. (2014) Federalizm, no. 3, p. 45-56. [in Rus.].

6. Barkhatov V.I., Pletnev D.A., Kapkayev YU.SH. (2019) Sotsium i vlast', no. 5 (79), pp. 65-83. [in Rus.].

7. Barkhatov V.I., Bents D.S. (2019) Upravlenets, vol. 10, no. 3, pp. 83-93. [in Rus.].

8. Vorotnikov A.M. (2000) Ekonomicheskiye strategii, no. 5-6, p.144. [in Rus.].

9. Ryazanov V. (2013) Ekonomist, no. 8, p. 3-40. [in Rus.].

10. Seliverstov V.Ye., Bandman M.K., Guzner S.S. (1996) Region: ekonomika i sotsiologiya, no. 1, p. 6. [in Rus.].

11. Shastitko A.Ye. (2009) Baltiyskiy region, no.1 (1), p. 11-31. [in Rus.].

12. El-Erian M.A. (2010) Navigating the New Normal in Industrial Countries. The Per Jakobsson Lecture, Per Jacobsson Foundation. Washington, D.C., available at: https://www.imf.org/external/np/speeches/2010/101010.htm (accessed 12.03.2020).

13. McNamee R. (2004) The New Normal: Great Opportunities in a Time of Great Risk. New York, Portfolio Hardcover, 272 p.

14. Pletnev D.A. (2018) Vestnik Chelyabinskogo gosudarstvennogo universiteta, no. 7 (417), pp. 211-218. [in Rus.]. 